\title{
Gênero e direito à cidade a partir da luta dos movimentos de moradia
}

\author{
Gender and right to the city based \\ on the struggle of housing movements
}

Diana Helene [I]

\section{Resumo}

A partir de uma releitura feminista, é analisado como as dificuldades de acesso à moradia no Brasil, marcadas pela histórica exclusão da terra e do mercado de trabalho das camadas mais pobres, abarcam condições ainda mais dramáticas quando se é mulher e piores ainda, quando se é mulher e negra. Por meio de narrativas femininas sobre suas histórias de vida dentro dos movimentos de moradia, demonstra-se de que maneira estes se estabelecem como um espaço potencializador para seu empoderamento e autonomia: da reestruturação das hierarquias de poder dentro do espaço privado e da segurança contra a violência doméstica à reapropriação do espaço público/político, engendrando uma luta por direito à cidade marcada por segregações de classe, raça e gênero.

Palavras-chave: habitação; gênero; moradia; movimentos sociais; direito à cidade.

\begin{abstract}
Difficulties in access to housing in Brazil, marked by the historical exclusion of the poor from the land and by their difficulties in accessing the labor market, encompass conditions that are even more dramatic when the person is a woman - and even worse conditions when the woman is black. In this scenario, the housing movements, composed mostly of women, establish themselves as a potentializing space for their empowerment and autonomy. This paper will address significant gains women have in their lives when they participate in these social movements, such as the restructuring of power hierarchies within the private space, safety against domestic violence, re-appropriation of the public/political space, among others.
\end{abstract}

Keywords: housing; genre; home; social movements; right to the city. 


\section{Introdução}

Nos últimos anos, vêm crescendo a importância do papel das mulheres e a visibilidade da luta feminista nos movimentos sociais organizados existentes. Surgem grupos, comitês e rodas de conversa dentro de movimentos tradicionais, como o movimento sem-terra e sem-teto, realizando ações específicas e destinadas ao público feminino. A inserção da luta feminista nos movimentos sociais tradicionais - anteriormente uma questão considerada não prioritária para a luta anticapitalista, ou mesmo chamada de uma questão "identitária" e "não estrutural" (da mesma forma que eram acusadas as lutas do movimento negro e/ou queer) - aponta para o crescimento de novas formas de engajamento, debate e atuação militante; demonstrando também como, recentemente, os movimentos sociais estão reconhecendo e encampando diferentes lutas, numa mesma perspectiva, e costurando embates contra as diversas opressões que se estruturam no espaço urbano. No caso específico dos movimentos de moradia, desvela questões importantes para perceber, para além da associação direta do gênero feminino ao espaço doméstico, os fatores que mobilizam as mulheres como as principais integrantes desses movimentos sociais.

Na minha experiência com diversos movimentos sociais de luta por moradia, ${ }^{1}$ apesar da expressiva quantidade de mulheres constituintes das comunidades dessas ocupações (visivelmente a maioria dos ocupantes), a questão de gênero e/ou luta feminista não aparecia inicialmente nos discursos das minhas interlocutoras. Embora muitos relatos apresentados aqui sejam analisados como formas de empoderamento feminino dentro da dinâmica das ocupações, essa ideia não estava presente nos espaços de militância de moradia até recentemente. No entanto, nos últimos anos, vêm crescendo essa importância e a sua visibilidade nesses movimentos sociais. Além de iniciarem a formação de espaços específicos para discussões de gênero dentro das organizações, começam a aparecer ações e até mesmo ocupações exclusivamente femininas, com o objetivo de acolher mulheres em situação de vulnerabilidade e de debater as especificidades das desigualdades de gênero no contexto da luta por moradia.

Um exemplo é a Ocupação "Tereza Benguela", uma ocupação realizada em 2017 em São Paulo, pelo Movimento dos Trabalhadores Sem-Teto - MTST. Segundo Claudia Garcez, coordenadora estadual do movimento, as discussões feministas são recentes dentro da organização: " a gente não discutia essas coisas dentro do movimento - apesar de a gente ver a valorização da mulher dentro dos espaços -, era uma coisa mais silenciada e a gente não ia para o enfrentamento". Foi, a partir de 2016, depois da agressão violenta de uma moradora por seu companheiro na ocupação "Esperança Vermelha", que se formaram rodas de conversa como estratégia de combate à violência sobre a problemática de gênero. Essas rodas propagaram o tema para as outras ocupações do movimento, culminando na ocupação "Tereza Benguela", localizada em um prédio abandonado da Cohab, onde as mulheres do movimento criaram um espaço de convivência e acolhimento para mulheres. ${ }^{2}$

Independentemente do debate feminista estar inserido de forma mais sistemática dentro das pautas de militância dos movimentos de luta por moradia, as relações entre 
empoderamento feminino e os ganhos de autonomia das mulheres ao participarem desses movimentos são prementes e envolvem fatores relacionados à formação do capitalismo e das cidades no tocante às desigualdades de gênero, como veremos adiante.

\section{A formação do capitalismo e as desigualdades gênero}

A epistemologia feminista e o "gênero" enquanto categoria de análise surgem no final do século XX como um ato político: reivindicar certo campo de definição e insistir no "caráter fundamentalmente social das distinções baseadas no sexo" (Scott, 1988). A partir de então, é colocado à tona que as relações desiguais entre homens e mulheres não são "naturais", mas sim estabelecidas por meio das relações sociais. A partir do momento que as militantes, teóricas e cientistas feministas colocam em pauta que a subordinação da mulher não é "biológica" nem justa, e sim construída socialmente por meio de relações de poder, surgem novas teorias para explicar de que forma se chegou a essa condição e como ela se mantém (Piscitelli, 2002). São revisadas, então, diversas teorias sociais, das quais destacamos, aqui, a formação do capitalismo.

Nesse sentido, o livro Calibã e a bruxa: mulheres, corpo e acumulação primitiva, de Federici, destaca-se por relacionar o surgimento do capitalismo com a maior guerra contra muIheres da história: a caça às bruxas dos séculos XVI e XVII. A obra descreve a formação do proletariado incluindo a degeneração das mulheres e a colonização como partes estruturantes do capitalismo, instituindo a divisão de trabalho a partir das relações sociais de classe, sexo e raça: "a definiç̧ão da negritude e da feminilidade como marcas da bestialidade e da irracionalidade correspondia à exclusão das mulheres na Europa - assim como das mulheres e dos homens nas colônias - do contrato social implícito no salário, com a consequente naturalização de sua exploração" (Federici, 2017, p. 36).

A caça às bruxas foi uma tentativa coordenada de degradar, de demonizar e de acabar com o poder social das mulheres: foi destruído todo um universo de práticas femininas, de relações coletivas e de sistemas de conhecimento que haviam sido a base do poder das mulheres na Europa pré-capitalista (ibid., pp. 291-292). Para isso, estabeleceu-se uma luta contra a solidariedade e as relações comunais estabelecidas entre mulheres. As amizades femininas tornaram-se objeto de suspeita - "uma subversão da aliança entre marido e mulher" -, e as relações de amizade e amor femininas foram demonizadas. Federici destaca, ainda, que é justamente nesse período que a palavra gossip (fofoca), que antes significava "amiga", transforma-se em um termo pejorativo (Ibid., pp. 334-335).

Nos julgamentos, a "má reputação" era prova de culpa. Era considerada bruxa a mulher "libertina" e "promíscua", aquela que praticava sua sexualidade fora dos vínculos do casamento e da procriação. ${ }^{3} \mathrm{~A}$ bruxa era também a mulher rebelde que "respondia, discutia, insultava e não chorava sob tortura". Uma ideia da personalidade feminina que havia se desenvolvido no contexto de luta contra o poder feudal, quando as mulheres atuaram à frente dos movimentos, muitas vezes organizadas em 
associações femininas, apresentando um desafio crescente à autoridade masculina e à Igreja. Dentre estas, destacam-se, ainda, as camponesas, pobres e as anciãs, que eram símbolos da cultura e do saber popular (Ibid., pp. 332-333):

Embora a caça às bruxas estivesse dirigida a uma ampla variedade de práticas femininas, foi principalmente devido a essas capacidades - como feiticeiras, curandeiras, encantadoras ou adivinhas - que as mulheres foram perseguidas, pois, ao recorrerem ao poder da magia, debilitavam o poder das autoridades e do Estado, dando confiança aos pobres em sua capacidade para manipular o ambiente natural e social e, possivelmente, para subverter a ordem constituída. (Ibid., pp. 314 e 348)

Para isso, a caça às bruxas usou a imprensa, as artes e outros meios de comunicação, gerando uma psicose em massa na população. Os dramaturgos, literatos, pintores e outros intelectuais dos séculos XVI e XVII pintaram a imagem dessa mulher diabólica, que atormentava vizinhos e oferecia pequenos bebês ao demônio. Foi criada, ainda, a imagem de uma série de vilãs: a esposa desobediente, a fofoqueira, a bruxa e a puta. Uma depreciação simbólica, literária e cultural que estava a serviço de um projeto de expropriação (ibid., p. 299). Os juristas, os magistrados e os demonólogos foram os que mais contribuíram nesse sentido. Jean Bodin, famoso jurista francês do século XVI, afirmava: "devemos disseminar o terror entre algumas, castigando muitas" (Jean Bodin apud ibid., p. 333).

A punição pública era uma das formas de estabelecer o controle a partir do horror e do medo. A forma mais conhecida era a queima de mulheres vivas até sua morte no espaço público. Mas havia outras formas de punição dirigidas especialmente às mulheres. Uma forma emblemática foi a criação de uma máscara, conhecida como "rédea de bruxa" ou "freio da fofoca": um instrumento de punição, tortura e humilhação pública. 0 dispositivo era um focinho em uma estrutura de ferro, que encerrava a cabeça com uma mordaça para caber na boca e comprimir a língua com uma ponta afiada que impedia a fala, pois movimentá-la causava laceração. Essa "engenhoca de ferro empregada para punir mulheres de língua afiada" foi concebida no século XVI como uma punição para suspeitas de feitiçaria, "megeras" ou "reclamonas". Além da máscara, a mulher carregava uma placa que informava o crime que havia cometido. A pessoa era colocada em um lugar público e, muitas vezes, espancada pelas pessoas que passavam (ibid., p. 201). ${ }^{4}$

Foi a demonização social e o horror das punições públicas e fogueiras que forjaram os ideais capitalistas de feminilidade e de domesticidade. A partir da negatividade em torno da imagem da bruxa, foi constituído seu oposto: a mulher e esposa ideal - passiva, de poucas palavras, ocupada em suas tarefas domésticas, seres inferiores, assexuados e obedientes (ibid., p. 334).

Essa subjugação e extermínio de mulheres estabeleceram também a divisão sexual do trabalho capitalista como conhecemos atualmente, na qual as funções destinadas às mulheres foram estruturadas como inferiores, não vistas como "trabalho" e, por essa razão, sem valor econômico. De acordo com Kergoat, a reorganização do trabalho a partir do patriarcado seguia dois princípios: a separação radical entre atividades ditas "femininas" 
e "masculinas" e a sua hierarquização, estabelecendo uma relação de poder entre elas. Assim, uma enorme massa de trabalho passa a ser realizada gratuitamente pelas mulheres, um trabalho invisibilizado, realizado em "nome da natureza, do amor e do dever maternal" (Kergoat, 2003, p. 57). Como descreve a historiadora Michelle Perrot:

0 século XIX acentua a racionalidade harmoniosa dessa divisão sexual. Cada sexo tem sua função, seus papéis, suas tarefas, seus espaços, seu lugar quase predeterminados, até em seus detalhes. Paralelamente, existe um discurso dos ofícios que faz a linguagem do trabalho uma das mais sexuadas possíveis. "Ao homem, a madeira e os metais. À mulher, a família e os tecidos". [...] 0 século XIX levou a divisão das tarefas e a segregação sexual dos espaços ao seu ponto mais alto. Seu racionalismo procurou definir estritamente o lugar de cada um. (Perrot, 1988, pp. 178 e 187)

Dessa forma, Federici demonstra como a chamada "acumulação primitiva capitalista" também se constituí dessa hierarquia de poder e do ocultamento do trabalho não pago das mulheres. Isso porque permitiram ao capitalismo "ampliar imensamente 'a parte não remunerada do dia de trabalho' e usar o salário (masculino) para acumular trabalho feminino" (Federici, 2017, p. 232). Para Perrot (1988), essa sociedade não poderia crescer e se reproduzir sem o "trabalho não contabilizado, não remunerado da dona de casa" ( p. 214). Isto é, a divisão sexual do trabalho e a opressão de gênero são partes indissociáveis da formação do capitalismo, e não é possível pensar uma superação desse sistema sem levar isso em conta:
Foi a partir dessa aliança entre os artesãos e as autoridades das cidades, junto com a contínua privatização da terra, que se forjou uma nova divisão sexual do trabalho [...] que definia as mulheres em termos - mães, esposas, filhas, viúvas que ocultavam sua condição de trabalhadoras e davam aos homens livre acesso a seus corpos, a seu trabalho e aos corpos e ao trabalho de seus filhos. De acordo com esse novo contrato social-sexual, as mulheres proletárias tornaram-se para os trabalhadores homens substitutas das terras que eles haviam perdido com os cercamentos, seu meio de reprodução mais básico e um bem comum de que qualquer um podia se apropriar e usar segundo sua vontade. (Federici, 2017, p. 191)

É preciso ressaltar que, mesmo quando trabalhadora em atividades remuneradas, seu trabalho era desvalorizado: as remunerações femininas são consideravelmente menores, e suas condições de permanência e/ou desenvolvimento de uma carreira são obliteradas pelas tarefas domésticas e de cuidado, dificultando suas possibilidades de ganhos reais em atividades pagas. Segundo Perrot, "a participação feminina no trabalho assalariado é temporária, cadenciada pelas necessidades da família, a qual comanda, remunerada com um salário de trocados, confinadas às tarefas ditas não qualificadas, subordinadas e tecnologicamente específicas" (Perrot, 1988, p. 187). Para Safiotti (1979, p. 35), a mulher é "perifericamente situada no sistema de produção".

Sem a possibilidade de ter seu próprio capital em um sistema no qual este define as bases da sobrevivência, criaram-se as condições materiais para a sujeição das mulheres e para a apropriação de seu trabalho pelos homens. 
A partir de então, o casamento torna-se uma "verdadeira carreira" para a mulher: "as muIheres teriam que suplicar aos homens 'que não Ihes tirassem a honra', a única propriedade que Ihes restava" (Federici, 2017, pp. 195 e 198).

\section{Feminização da pobreza e 0 acesso à moradia no Brasil}

No contexto brasileiro, entre os fatores que podemos associar a participação massiva de mulheres em movimentos de moradia - e, vale dizer, em todos os movimentos sociais - destaca-se a chamada "feminização da pobreza". De acordo com a Pnad/IBGE (2015), o rendimento médio mensal real de todos os trabalhos dos homens com mais 15 anos de idade foi de $R \$ 2.058$ (e de $R \$ 2.509$, no caso dos homens brancos) e o das mulheres, de $\mathrm{R} \$ 1.567$ (e de $\mathrm{R} \$ 1.027$, no caso de mulheres negras). Outra pesquisa, do Inter-American Development Bank (IDB) 2009, no Brasil, indica que mulheres de mesmo grau de instrução e faixa etária, que ocupam os mesmos cargos que homens, ganham em média 30\% menos que eles.

É preciso, ainda, levar em conta a quantidade de mulheres trabalhando sem remuneração ou desempregadas, em número consideravelmente maior que os homens. No caso das mulheres negras, esse fato é ainda mais grave. Elas recebem menos da metade do valor do salário dos homens brancos, são as mais suscetíveis ao desemprego e são o maior contingente de empregadas sem carteira assinada.

Tanto mulheres brancas como negras têm trajetórias em ocupações de menor prestígio e/ou com más condições de trabalho, marcadas pela instabilidade e vulnerabilidade (Hirata, 2014, pp. 63-64). Além disso, quase a metade $(46,3 \%)$ está concentrada nos serviços domésticos, de educação, de saúde, sociais e comunitários (Itikawa, 2015, p. 40). Vale dizer que, esse grupo, relacionado às chamadas tarefas reprodutivas, ${ }^{5}$ constitui ainda as atividades laborais mais informalizadas, mal remuneradas e desvalorizadas no mundo do trabalho. Entre elas, a trabalhadora doméstica vai constituir a categoria mais vulnerável, devido à baixa remuneração e ao grau de precariedade. Além disso, a quantidade de trabalhadoras domésticas negras é o dobro das não negras (Proni e Gomes, 2015; Pinheiro, Fontoura e Pedrosa, 2012, p. 95).

Ademais, em relação às atividades não remuneradas, mais de $90 \%$ das mulheres declararam realizar atividades domésticas. As muIheres trabalham em média oito horas por semana a mais que os homens. Os termos "dupla jornada", "acumulação" ou "conciliação de tarefas" mantêm a ideia do trabalho da esfera reprodutiva, regenerativa e de cuidado como se fosse somente um apêndice do trabalho assalariado (Hirata, 2014).

Sobrecarregadas de trabalho não pago e situadas marginalmente no mundo do trabalho, o acesso ao mercado de moradia no Brasil, já inalcançável para muitas famílias, é ainda mais difícil quando se é mulher (Helene e Lazarini, 2018). Somam-se, às desigualdades estruturais de gênero, as características específicas de constituição da sociedade brasileira: as dificuldades de acesso a terra e a inserção no mercado de trabalho das populações mais pobres, sobretudo aquelas descendentes dos negros escravizados. Devido às condições estabelecidas sobre a herança da escravidão 
no Brasil e ao processo de transição para o trabalho assalariado capitalista, estruturaram-se "caminhos que seriam determinantes na exclusão histórica de brasileiros na terra, no direito ao trabalho e nos demais direitos sociais" (Itikawa, 2015, p. 37).

Nesse contexto, a informalidade foi uma tática popular para autorresolução desses problemas. Uma imagem expressiva do quadro de exclusão social e segregação das cidades brasileiras e latino-americanas e situação comum a praticamente todos os relatos obtidos: antes de entrarem no movimento de luta por moradia, praticamente todas as militantes foram moradoras de favelas e outras forma de habitação informal. Segundo Itikawa, essas mulheres "são obrigadas a viver em constante êxodo urbano, na moradia e no local do trabalho" e "confirmam uma vida inteira nas periferias: são sistemáticas e sucessivas mudanças no tipo de ocupações informais, bem como êxodos intraurbanos na moradia e no trabalho" (ibid., pp. 95 e 96).

\section{A divisão sexual do trabalho nas cidades}

Para além das dificuldades de acesso à moradia adequada, as dificuldades de morar na rua, "virar-se" ou "morar de favor" também são mais difíceis para o gênero feminino. Não é apenas o perigo da violência sexual, ameaça constante na vida de uma mulher, que oblitera de forma predadora suas condições de uso do espaço público e da sua vida urbana. Mas é também por serem designadas à posição daquelas que cuidam cotidianamente das crianças, idosos e outros, o espaço da casa eleva-se a uma importância muito maior. Isto é, para elas, a moradia significa muito mais que um abrigo ou uma mercadoria, é um espaço essencial de proteção de si e de manutenção daqueles dependentes de seus cuidados. 0 valor de uso da moradia para o gênero feminino envolve particularidades que elevam sua importância para muito além de seu valor de troca.

Por esse mesmo motivo, mesmo quando se tem onde morar, a importância da localização se destaca. A questão de gênero aparece na relação entre moradia e o contexto urbano, devido ao fato de os espaços predominantemente voltados para habitação, e marcados pelas atividades domésticas, constituírem-se como espaços nos quais as mulheres estão majoritária, cotidiana e constantemente presentes. Baseado no que vimos anteriormente sobre a chegada do modelo de produção capitalista e sua relação com as desigualdades de gênero, podemos afirmar que, na formação das cidades capitalistas, espacializou-se a nova divisão sexual do trabalho. Isto é, que uma organização urbana generificada também nasceu durante a transição entre feudalismo e capitalismo. 0 êxodo rural e a separação entre trabalho e moradia trazidos pela industrialização são indissociáveis das dicotomias de gênero, pelas quais foram estruturadas as hierarquias entre trabaIho doméstico e trabalho produtivo.

A estruturação do espaço urbano capitalista é marcada pela gradativa especialização do trabalho, da qual, destacamos aqui, aquela advinda da divisão sexual. Dessa forma, é preciso lembrar que, nas sociedades pré-capitalistas e no início do processo de industrialização, o que caracterizava a vida das famílias era a integração entre as funções domésticas 
e o trabalho produtivo, realizados em um único ambiente (fato que ainda permanece em algumas regiões do Brasil, conforme Alves, 2013). A industrialização estrutura no espaço urbano uma gradativa separação entre moradia e trabalho, surgindo, para isso, arquiteturas específicas para cada função. 0 artesão, por exemplo, não mais realiza seu trabalho em uma oficina no primeiro piso ou aos fundos da casa. Ele também não mais produz alimentos e outros insumos para sua subsistência no entorno de sua residência (agricultura e criação de animais). Ao se tornar operário, ele passa a consumir produtos produzidos fora de seu espaço de morada (prontos ou industrializados); e a circular por ambientes separados: a fábrica (local de trabalho); mercados/lojas/vendas (local de consumo); e um outro local onde estabelece sua residência, alojamento, casa (local de moradia); separados funcionalmente e espacialmente no contexto urbano. Isto é, acontece um duplo movimento de separação e especialização dos espaços, no qual os locais de trabalho/produção já não são mais os da vida doméstica.

Nesse momento de separação entre espaços de produção, consumo e moradia, também se estrutura espacialmente o que é considerado público e o que é privado, ao mesmo tempo que se organizam esses espaços de acordo com a divisão sexual do trabalho: o público/produtivo como um espaço masculino e o privado/doméstico como feminino. Segundo Perrot (1988, p. 190), "a novidade de sua posição [da dona de casa] no século XIX reside na acentuação da divisão do trabalho e na separação dos locais de produção e consumo. 0 homem na fábrica, a mulher em casa, ocupando-se do doméstico". Isto é, a produção distancia-se quase inteiramente da esfera doméstica para a pública nos últimos 300 anos, e a intimidade passa a ser vista como caracteristicamente doméstica. Segundo Okin, "'o privado' sendo usado para referir-se a uma esfera ou esferas da vida social nas quais a intrusão ou interferência em relação à liberdade requer justificativa especial, e 'o público' para referir-se a uma esfera ou esferas vistas como geralmente ou justificadamente mais acessíveis" (Okin, 2008, p. 306).

No entanto, é importante sublinhar que, apesar de o espaço doméstico ser relacionado às atividades realizadas pelas mulheres, isso não quer dizer que este é um espaço de poder delas. No capitalismo, a noção de espaço privado é constituída como um pré-requisito da intimidade da família. E, dentro da unidade familiar, estrutura-se mais uma relação generificada de poder. Ademais, família como uma entidade singular tem direitos de não sofrer interferência do Estado no que se refere à regulação e ao controle dos membros de sua esfera privada, o que reforça a autoridade dos maridos sobre as esposas e dos pais sobre os filhos, como sua propriedade. A privacidade no espaço privado acaba sendo um direito dos indivíduos adultos e chefes de família masculino de poder sobre aqueles que, seja pela idade, gênero ou condição de servidão, são vistos como legitimamente controlados por eles, tendo sua existência limitada à esfera de privacidade do patriarca. Isto é, não há uma noção de que esses membros subordinados tenham seus próprios direitos à privacidade, para os quais o lar "pode ser o mais perigoso dos lugares" (ibid., pp. 306, 322 e 323$).$

Tais condições podem explicar o fato de o espaço doméstico se constituir como um dos 
espaços no qual prevalecem os maiores números de violência contra a mulher, na maior parte das vezes realizada por parentes, pessoas próximas da família, parceiros sexuais e companheiros. Segundo o "Mapa da Violência 2015: Homicídio de mulheres no Brasil" (Waiselfisz, 2015), 50,3\% das mortes violentas de mulheres são cometidas por familiares e $33,2 \%$ por parceiros ou ex-parceiros das vítimas. No caso de agressões físicas e sexuais, também predomina a violência doméstica. Parentes imediatos ou parceiros/ex-parceiros são responsáveis por $67,2 \%$ dos atendimentos. ${ }^{6}$ Outro dado importante é o local em que ocorrem as agressões. No caso da violência não letal, a residência é o local privilegiado para ambos os sexos. No entanto, é significativamente superior para o sexo feminino $(71,9 \%)$ em relação ao masculino $(50,4 \%)$. Em segundo lugar, a rua é local de ocorrência de $15,9 \%$ das violências no caso feminino, contra $30,6 \%$ dos atendimentos masculinos. Da mesma forma, no caso dos homicídios, metade dos homicídios masculinos acontece na rua $(48,2 \%)$, enquanto, em relação aos femininos, essa proporção é bem menor (31,2\%); no caso das mulheres, o domicílio da vítima também é relevante $(27,1 \%)$, enquanto para os homens configura apenas $10,1 \%$ dos casos. Esses dados indicam uma domesticidade relacionada à violência contra a mulher (ibid., pp. 29-51).

Essa questão é fundamental para qualificar a divisão de gênero entre público e privado para além da ideia do espaço privado como feminino e o público como masculino. Se o espaço privado fosse um local de refúgio seguro para as mulheres, que são constantemente excluídas do espaço público, esse não seria o local de maior violência e morte feminina. Ou seja, entender que tanto o espaço público como o privado são marcados por hierarquias de gênero que dão poder àqueles reconhecidos como homens. Podemos afirmar, ainda, que o grau de sujeição (poder legitimado culturalmente) das mulheres em relação aos homens é correlato ao grau em que a dicotomias público/doméstico, masculino/feminino, cultura/natureza e público/privado são destacadas. Essas dicotomias recebem tanto conotações como são usadas para organizar a vida social de maneiras distintas em diferentes períodos/territórios (ibid., p. 318). Isto é, a criação das noções capitalistas de público e privado, em consonância com a divisão sexual do trabalho, incidiu diretamente na constituição de uma organização urbana generificada, que instituiu os espaços públicos e privados a partir da separação entre espaços produtivos e espaços reprodutivos.

Dessa forma, no contexto urbano, em função da dupla jornada de trabalho realizada pelas mulheres e das características relacionadas às tarefas da esfera reprodutiva, as desigualdades urbanas, os problemas relacionados à infraestrutura e aos equipamentos públicos as afetam muito mais do que os homens (Gonzaga, 2011; Itikawa, 2015; Latendresse, 2005; Tavares, 2015; Santoro, 2008; Silva, 2003). Por exemplo, se tomarmos como ponto de observação a mobilidade, a dinâmica masculina costuma ser mais pendular e linear entre moradia e trabalho. A principal atividade dele diária é o trabalho produtivo, formal ou informal. Já a mulher, em geral, faz não só o trabalho produtivo como também é majoritariamente responsável pelo trabalho reprodutivo. Por essa razão, o número de deslocamentos realizados pelas mulheres é mais intenso que o dos homens. Elas estão encarregadas do trajeto 
dos filhos à escola, da compra de insumos alimentícios, da limpeza e do cuidado do entorno da moradia, entre outras tarefas relacionadas ao ambiente doméstico. Por isso, tendem a fazer viagens mais curtas e diversas, espalhadas durante o dia em horários diferentes. Quantos maiores as dificuldades e as distâncias entre esses diferentes destinos, piores as condições que estas enfrentam:

Em muitas comunidades onde falta água, por exemplo, são as mulheres que caminham vários quilômetros diariamente carregando baldes ou latas. São elas também que dedicam várias horas de seus dias para levar filhos à escola ou idosos a postos de saúde. A ausência destes e de outros itens, portanto, reduz o tempo disponível das mulheres para se dedicarem a outras atividades que garantam sua independência, além de impor maior desgaste físico, afetando sua saúde. (Rolnik et al., 2011, p. 15)

Por essa razão, tanto a mulher trabalhadora domiciliar quanto a do espaço público sentem o peso da mobilidade urbana na medida em que recai sobre elas a responsabilidade pelo trabalho reprodutivo e, dessa forma, precisam interromper seu trabalho para se "dividir" com a tarefa de cuidar dos familiares e da casa, bem como de prover insumos para viabilizar sua atividade. A soma de todos os deslocamentos urbanos subtrai o tempo $\mathrm{e}$, consequentemente, os rendimentos das trabaIhadoras informais, subordinando-as a um regime desfavorável em comparação aos empregados formais e homens. (Itikawa, 2015, p. 14)

Ademais, o urbanismo capitalista, ao contrário de propor soluções para a realização dessas atividades de forma mais adequada, usualmente não considera a problemática que as envolve. A mobilidade não é pensada para trajetos pequenos e polarizados no entorno dos bairros habitacionais, mas, sobretudo, para os trajetos longos/pendulares entre residência e trabalho. Podemos observar tal fato de forma clara na estrutura viária típica de nossas cidades, radial, que liga centro e periferia, mas que não conecta entre si os bairros não centrais, sendo necessário, muitas vezes, um transporte até a área central para se locomover a um bairro vizinho, no qual se localizaria a escola das crianças, o mercado ou o posto de saúde mais próximo. 0 próprio bilhete de transporte poderia ser pensando de outra forma, para que reduzisse o custo da realização de diversas viagens no mesmo dia.

Isto é, a urbanização desenvolvida pela sociedade capitalista privilegia consideravelmente as tarefas relacionados à produção no lugar das necessidades, espaços e atividades relacionadas a realização das tarefas reprodutivas. As intervenções urbanas, o urbanismo e o planejamento urbano e territorial são constituídos de modo a auxiliar a produção capitalista (o fluxo de mercadorias, a circulação de trabaIhadores e o lucro); e não o bem-estar cotidiano de seus habitantes.

Outro motivo deve-se ao fato de os urbanistas, em geral homens, desconhecerem as necessidades cotidianas ligadas às atividades reprodutivas, em função da separação radical do trabalho entre homens e mulheres e o consequente alijamento masculino dessas atividades. Fato este brilhantemente denunciado pela célebre urbanista Jane Jacobs. Mãe de três filhos, Jacobs vivia a cidade a partir da realização das atividades de seu dia a dia, conectadas com as tarefas destinadas ao gênero feminino na reprodução da vida 
cotidiana. E pôde trazer à tona uma crítica ao que se produzia pelo urbanismo até então, feito, sobretudo, por homens brancos de países do Norte, que não estavam presentes nos espaços da reprodução cotidiana da vida na cidade, e sim em seus escritórios, vendo e desenhando a cidade "de cima": "planejadores e projetistas são, em sua maioria, homens. Estranhamente, eles criam projetos e planos que desconsideram os homens como integrantes da vida diária e normal de onde quer que haja moradias" (Jacobs, 2000, p. 91). Sua contribuição principal foi a crítica aos espaços monofuncionais, a falta de diversidade e de gente nas ruas e sua implicação para vitalidade, segurança e manutenção coletiva das crianças e de outros habitantes "esquecidos" no planejamento oficial. Sua crítica ecoa com os debates feministas atuais em torno do planejamento urbano, que afirmam que o zoneamento modernista separou e distanciou os locais de "trabalho" das zonas residenciais, isolando as mulheres nos espaços destinados à esfera doméstica e afastando, ainda mais, os homens das tarefas cotidianas de reprodução da vida: ${ }^{7}$

Os locais de trabalho e o comércio devem mesclar-se às residências se se tiver a intenção de que os homens, como, por exemplo, os que trabalham na rua Hudson ou próximo dela, estejam perto das crianças na vida diária - homens que participem da vida cotidiana normal [...] A oportunidade (que na vida moderna se tornou um privilégio) de brincar e crescer num mundo cotidiano composto tanto de homens como de mulheres é possível e comum para crianças que brincam em calçadas diversificadas cheias de vida [...] Os urbanistas parecem não perceber quão grande é a quantidade de adultos necessária para cuidar de crianças brincando. Parecem também não entender que espaço e equipamentos não cuidam de crianças. Estes podem ser complementos úteis, mas só pessoas cuidam de crianças e as incorporam à sociedade civilizada. (Ibid.)

0 planejamento urbano modernista funcionalista vai acentuar ainda mais o rebatimento da divisão sexual do trabalho no espaço da cidade, aprisionando as mulheres em determinados lugares, principalmente ao separar e hierarquizar substancialmente as áreas comerciais, industriais e residenciais (Silva, 2003). Ademais, no caso do Brasil, a separação de funções entre casa e trabalho nas cidades vai ser somada ao espraiamento, à dispersão e à extrema precariedade urbana dos espaços residenciais das classes mais pobres. Nessas condições, o que Henri Lefebvre chamou de "ideologia do habitat" (a propriedade da casa proletária no subúrbio/periferia como forma de suburbanização dos operários) exerce uma opressão adicional quando se é mulher. Segundo o autor, tal ideologia implicou a prática do habitar dos mais pobres como meramente residencial, separando-o da vida e do habitar urbano, criando uma hierarquia espacial entre as classes, as propriedades e os proprietários, a partir do processo de descentralização/espraiamento. Em resultado, aconteceu o afastamento do proletariado da cidade e a sua consequente perda do sentido de vida urbana, fazendo a sua "consciência urbana" se dissipar (Lefebvre, 1991, p. 17). Tal situação vai ser ainda mais extrema no caso das mulheres, que tampouco usufruem minimamente das áreas de centralidade por estarem alijadas das atividades produtivas e do espaço público e ainda sofrem cotidianamente com a precariedade 
desses locais distantes, monofuncionais, com infraestrutura urbana e equipamentos públicos ausentes ou insuficientes.

Nesse sentido, a problemática que envolve a questão urbana relacionada à habitação tem um impacto generificado. A qualidade dessa moradia, sua localização e distância de serviços públicos de transporte, escolas, postos de saúde e parques, bem como suas condições em relação ao saneamento básico, água encanada/ potável vão afetar a vida cotidiana das mulheres e a realização das tarefas relacionadas ao seu gênero (Alfonsin, 2006). Duque de Caxias, na região metropolitana do Rio de Janeiro, uma cidade constituída enquanto subúrbio periférico da capital carioca, é um exemplo de como a precariedade urbana que circunda o universo da moradia vai impactar o gênero feminino. As características relacionadas à constituição dessa cidade enquanto "cidade-dormitório" e zona de sacrifício ambiental ${ }^{8}$ (Pereira, 2013) atingem de forma diferenciada as mulheres e as crianças moradoras da região, que sofrem com doenças relacionadas à poluição ambiental e à debilidade do saneamento de forma mais expressiva que seus pares masculinos adultos. ${ }^{9}$ Por estarem mais presentes e realizando atividades vinculadas organicamente ao seu espaço de moradia, as mulheres acabam sendo mais impactadas pela precariedade urbana e ambiental dessas áreas periféricas: " [...] o agravo das condições sanitárias e, com ele, a escassez ou poluição da água e a disseminação de doenças impactam diretamente, e, sobretudo, o trabalho e a vida das mulheres, responsabilizadas historicamente pela gestão do cotidiano doméstico" (Faustino e Furtado, 2013, p. 35). Nesse sentido, podemos dizer que, no Brasil, os subúrbios, cidades-dormitórios, periferias e cidades-satélites são, ao mesmo tempo, territórios negligenciados pelas políticas públicas urbanas e espaços de habitação das classes mais pobres, demarcadamente caracterizados por gênero e raça.

\section{Autonomia e empoderamento nos movimentos de moradia}

A genealogia dos movimentos de moradia relaciona-se com o fim da ditadura militar no Brasil, quando acontecem as primeiras ocupações organizadas de terra, os primeiros movimentos de luta pela urbanização e regularização fundiária nas favelas e o nascimento do movimento dos sem-terras urbanos (Gohn, 1991). A crise habitacional, as desigualdades urbanas estruturais e a falta de políticas públicas que garantissem o acesso ao solo urbano e à moradia motivaram, então, a população a se organizar em movimentos para lutar por melhores condições. Com o tempo, essas organizações passam a pautar a questão da moradia para além da casa em si, incluindo sua localização urbana, o que demonstra que a luta por moradia é também uma luta por direito à cidade. Assim, passam a realizar a ocupação de prédios vazios em áreas centrais, próximos a áreas com infraestrutura urbana, equipamentos públicos e aos locais de trabalho, engendrando uma reconquista do seu direito de morar em áreas com urbanização adequada (Helene, 2009; Andrade, 2013, p. 46).

É no cotidiano dessas ocupações - de terrenos ou imóveis vazios - que são construídas coletivamente resistências e outras formas de "morar", que estruturam novas 
alternativas às soluções ineficientes do Estado. A autogestão como base de organização das ocupações possibilita ainda uma experimentação de rompimento com lógicas capitalistas de produção e organização do espaço habitacional. Os valores debatidos e construídos coletivamente visam ao bem-estar da comunidade de ocupantes, em especial daqueles mais vulneráveis, dos quais destacamos aqui aqueles do gênero feminino. Faltam dados efetivos, mas, em geral, as mulheres são a maioria desses grupos. Ademais, a maior parte delas é visivelmente composta de mães e, entre elas, muitas mães monoparentais ("mães solteiras"):10

As mulheres são maioria. A luta pela moradia é muito mais do que propriedade para a gente. É uma questão de sobrevivência própria e dos nossos filhos. (Natalia Szermeta, coordenadora do MTST, 2018) ${ }^{11}$

Dentro do nosso grupo, do nosso movimento, a maioria é mulher.[...] Antigamente [fundação do grupo em 2001] era só mulher. Só mulher. Eram quinze muIheres na coordenação. [...] E hoje tem alguns homens envolvidos. (Ivanete de Araújo, coordenadora-geral do Movimento Sem-Teto do Centro - MSTC, 2011) $)^{12}$

Que às vezes um pai de família, quando vê a sua família naquela necessidade da moradia, ele tem vergonha de ir para um grupo de base, ficar lá sentado uma hora assistindo a reunião, e sempre quem vai são as mulheres. Aí vão, porque geralmente as mulheres vai uma, duas, três, na terceira reunião que ela consegue levar o marido para a reunião. Por isso que acontece, sempre as mulheres na frente. (Jomarina A. P. da Fonseca, coordenadora do MSTC, entrevista realizada pela autora em 2009)

Esse fato se deve a uma série de condições sociais relacionadas aos papéis de gênero designados às mulheres e à precariedade de acesso à moradia que elas enfrentam em função disso, como vimos anteriormente. Por essa razão, em 2011, a relatora especial da ONU, Raquel Rolnik, lançou a cartilha "Como fazer valer o direito das mulheres à moradia?" (Rolnik et al., 2011). 0 documento, fruto de uma pesquisa sobre políticas públicas relacionadas a habitação e gênero em diferentes países do globo, destaca sete pontos fundamentais para garantia do direito à moradia para as muIheres: habitabilidade (condições de habitação adequadas); disponibilidade de serviços, infraestrutura e equipamentos públicos; localização adequada; adequação cultural ("a forma de construir a moradia e os materiais utilizados na construção devem expressar tanto a identidade quanto a diversidade cultural dos moradores e moradoras") (ibid., p. 18); não discriminação e priorização de grupos vulneráveis ("idosos/as, crianças, pessoas com deficiência, pessoas com HIV, vítimas de desastres naturais, etc." (ibid., p. 20); custo acessível; e, por fim, segurança da posse. Este último item se articula com o direito a viver sem ameaças de remoção, de forma estável e segura. Mas também uma reparação histórica em assegurar o acesso das mulheres à habitação, como, por exemplo, preferenciar a titularidade feminina. Isso porque, em todo o mundo, a propriedade da terra e da moradia está, majoritariamente, nas mãos dos homens (ibid., pp. 8 e 9). ${ }^{13}$

A segurança de posse como um direito a ser garantido para as mulheres é também importante porque a feminização da pobreza e a dependência econômica - aliadas à necessidade de proteção daqueles responsáveis por seus cuidados $^{14}$ - costumam ser os principais fatores de manutenção de situações de violência 
doméstica. Isto é, a "casa" não é apenas o cenário, mas, muitas vezes o protagonista de um "enredo trágico: muitas mulheres não conseguem pôr um fim na relação com o agressor simplesmente por não terem pra onde ir com seus filhos" (ibid., p. 11). Segundo Rolnik, "para as mulheres, a não realização desse direito ou a sua violação têm consequências específicas, que não se verificam da mesma forma para os homens" (ibid., p. 5). 0 relato abaixo, realizado por uma integrante do movimento social União Nacional por Moradia Popular (UNMP), demonstra essa importância:

Tinha uma mulher. Ela não era coordenadora, nada disso, só participava e trabalhava. Era uma pessoa assertiva, forte; não era quieta ou amuada. Só que alguns momentos, percebíamos que ela tinha sofrido violência em casa. Nessa época não tinha nem trabalho social, então a gente tentou ver com alguém que fosse mais próximo dela pra tentar conversar e tal, só que ela não aceitava. Não conversava sobre isso com ninguém, mas era nítido que de vez em quando algo acontecia. Às vezes ela ficava sem aparecer, então sabíamos que havia uma situação ali, mas não tinha nada que a gente pudesse fazer. Durante a obra inteira ela não falou nada, não abriu a boca. Aí acabou 0 mutirão e foram fazer as entregas lá. $\mathrm{Na}$ hora de pegar a chave e ela perguntou pra coordenação: "Escuta, a festa vai ser sábado. Domingo eu posso mudar?". A maioria das pessoas ainda ia dar uma arrumada no piso, colocar cortina e tal. Mas pode né? A casa era dela. Aí ela chegou com a mudança e os filhos, passou uns dois dias e chega o marido lá, emputecido. Acho que foi umas $6 \mathrm{~h}$ da manhã e começou a bater na porta e a xingar no meio da rua. Ainda morava pouca gente no mutirão, aí o pessoal foi ver o que tava acontecendo. Juntou todo mundo na rua. E ela não abria a porta, não saiu pra rua. Aí uma das vizinhas foi lá falar com ela e ela falou: "Pode mandar embora, você viu ele carregando um tijolo por aqui?". Aí os homens foram lá e colocaram ele pra fora. Aí foi aquela choradeira né? a mulherada toda foi acudir ela. Ela disse "Enquanto eu não tinha um teto pra colocar meus fiIhos embaixo, eu nunca levantei a voz pra ele. Eu entrei no movimento esperando esse dia. 0 dia que eu pudesse não depender mais dele e ter um lugar pra colocar meus filhos. Agora ele não encosta mais a mão em mim". (Relato de Evaniza Rodriguez - UNMP, 2017) ${ }^{15}$

Esse relato demonstra a importância da luta por moradia e da garantia da segurança de posse para o empoderamento e autonomia econômica das mulheres, bem como a possibilidade de maior autonomia às mulheres na manutenção de sua integridade física perante as violências de gênero.

Em paralelo a essa questão, acontece também o empoderamento como sujeito político a partir da participação nos movimentos sociais de moradia, fato comum entre homens e mulheres que iniciam um processo de militância. A ocupação torna-se um espaço privilegiado de organização política da classe trabaIhadora, um local de experimentação de laços de solidariedade e autogestão, mas sobretudo de formação intelectual e política. Por isso a importância que os ocupantes dão à formação contínua dos moradores, que acontece de maneira teórica e prática, na autogestão coletiva do espaço. Podemos afirmar que a carência de moradia funciona em primeira instância como um núcleo aglutinador para, nas outras atividades cotidianas, resultar numa indagação sobre sua condição dentro do sistema capitalista 
(Helene, 2009, pp. 82-84). No caso das mulheres, esse empoderamento político abarca condições específicas. A conquista do espaço público/político a partir de sua participação em um movimento reivindicatório de direitos transforma substancialmente a autonomia dessas muIheres, já que este foi um espaço historicamente expropriado ao gênero feminino.

Nas narrativas dessas mulheres aparece como sua relação com o Estado, com as instituições e mesmo com seus maridos/companheiros/filhos/parentes mudou completamente após a participação nos movimentos. Muda a forma de ver a si mesma e a sociedade em que estão inseridas, suas condições de subalternidade como mulher e suas possibilidades de reivindicação perante o Estado e o espaço público, mas também perante suas relações pessoais, lutando contra as desigualdades sexuadas na esfera privada. 0 relato abaixo, da coordenadora geral de um movimento de moradia que atua ocupando edifícios na área central de São Paulo, demonstra de forma incisiva esse fato:

Às vezes meu marido está na cama e fala "Vida, pega um pouco de comida pra mim?" e eu "Não, vai lá. Aproveita e traz pra mim também. Estou com fome". [...] Ah e lembrando, antes de eu vir para o movimento eu tomava o maior chicote do meu marido. Apanhava muito. Muito. Eu me sentava e dizia "Bate, porque você é meu marido e você tem direito" [...]. "[marido falando] Hoje fulano foi brincar comigo na firma e eu disse: 'não brinque comigo, eu bati na mulher essa noite" [...] Quando eu passei a entender o movimento, participei de algumas formações e tal... quando ele veio para me dar [bater], ele deu a primeira mas o restante ele levou tudinho. Eu me lembro que ele falou assim, com a cara toda arranhada (eu cortei toda a cara dele na unha, e soquei bastante). [...] Aí ele falou: "Ai... como é que eu vou trabalhar com essa cara?". Eu falei "Você vai chegar na firma e você vai dizer: 'não brinca comigo hoje não porque eu estou azedo, estou nervoso, porque eu apanhei da mulher esta noite'. Você entendeu? Porque chega, eu não vou mais baixar a cabeça para você". E é assim, eu não abaixo a cabeça para homem nenhum. (Ivanete de Araújo.) ${ }^{16}$

Podemos observar no seu relato como a sua maneira de se ver dentro do casal/família mudou, e como passou a exigir tanto uma divisão mais igualitária das tarefas domésticas como o fim do poder violento do marido sobre seu corpo. Isto é, a independência econômica aliada à sua formação política foram fundamentais para compreender que marido não tem "direito" a ser violento, e que ela não precisa "baixar a cabeça" para nenhum homem. A consciência política é apoiada pela reestruturação da hierarquia de poder em não mais depender economicamente do marido para manter sua casa.

Segue outro exemplo, de outra moradora de um prédio ocupado no centro de São Paulo:

A partir do momento que eu vim para o movimento, eu aprendi muita coisa. Nossa, porque, quando eu morava lá na periferia né, eu trabalhava em casa de família, chegava o final de semana, aí eu vou lavar roupa, fazer isso, cuidar de casa né, a partir do momento que eu entrei e vim pra dentro do MTSC, eu aprendi muita coisa, coisas que eu nem sabia que existiam. Por exemplo, hoje em dia eu vou numa mesa de negociação, vou no gabinete de vereador, deputado, qualquer coisa né, vou sem medo né. Antigamente, 
meu Deus, pra chegar perto de um vereador, ou de um deputado era "a meu Deus, é coisa de outro mundo!". Hoje não, hoje eu já vou sem medo, às vezes acontece de ter alguma briga aqui e chama a polícia, quem é a coordenadora? Você vai na polícia? Vou, sem medo. No tempo que eu morava na periferia, eu via uma viatura eu já me apavorava, já me apavorava, é que aqui eu aprendi muita coisa, agradeço muito ao movimento, eu aprendi muito, eu acho que eu aprendo hoje, que eu tenho, que eu falo, tudo eu dou graças a Deus de ter conhecido o movimento de ter vindo fazer parte desse movimento. $E$ não só eu, toda a minha família. Eu agradeço muito. (Jomarina Pires da Fonseca, coordenadora do MSTC, entrevista realizada pela autora em 2009)

Podemos observar, aqui, como a participação de Jomarina no movimento e o cotidiano do espaço coletivo da ocupação transformaram sua relação com Estado e com o espaço público da política ("mesa de negociação", "gabinete do vereador", deputado, polícia, "qualquer coisa"), acarretando o seu apoderamento enquanto sujeito ativo no processo social. É interessante também as dicotomias de oposição que ela utiliza para demarcar como era sua situação antes de entrar no movimento: "quando eu morava lá na periferia", " trabalhava em casa de família", "vou lavar roupa, fazer isso, cuidar de casa né", " no tempo que eu morava na periferia, eu via uma viatura, eu já me apavorava" demarcando que a mudança em relação a sua participação na vida pública tem a ver com o fim de uma certa "alienação" ou isolamento ao qual estava submetida na periferia e nas tarefas domésticas. Isto é, reafirma uma ideia acerca das especificidades de empo- deramento feminino no caso dos movimentos de moradia que atuam nas áreas centrais: demonstra como ela estrutura, na sua história de vida, o momento da transformação na sua relação com o Estado e suas forças de repressão (a imagem da "viatura" associada à violência policial) a partir da participação no movimento, mas também no momento em que ela muda da periferia para área central da cidade. 0 mesmo tipo de relato em oposição a um passado no qual as mulheres se sentiam isoladas no âmbito privado da casa e a um certo espaço da cidade pode ser visto no relato abaixo, de uma moradora da Ocupação Mauá, no centro de São Paulo:

Com o apoio aqui que eu tenho [na ocupação], eu estou conquistando as coisas que eu quero. Que eu sonhei [ela conta de sua experiência em ter um negócio próprio, uma venda na ocupação]. [...] ... agora EU SONHO. Antes, lá [na periferia] eu nem sonhava, vivia aquela vidinha ali, de dona de casa, de cuidar de filho... (Raquel Guimarães Dutra, Ocupação Mauá MTSC coordenadora ASTC-SP) ${ }^{17}$

É importante dizer que isso não significa que essas mulheres deixaram de realizar as atividades domésticas, mas que não estão mais as realizando sozinhas e/ou que estão realizando outras atividades para além das tarefas que realizavam até então, sobretudo aquelas fora do solitário âmbito privado. Além disso, é comum o relato de como o espaço coletivo da ocupação auxilia nas tarefas domésticas, como, por exemplo, o revezamento dos moradores nas tarefas de limpeza e de cuidado de crianças, sobretudo facilitando a situação de vida de mães monoparentais 
e idosos sem família. Como, por exemplo, no relato a seguir:

E as próprias crianças, tem uma história assim, que eu sempre arrumo um grupo e levo na Pinacoteca com as crianças. Mas quando a gente passa assim, uns dois três meses sem ir, eles já ficam me perguntando "o tia, quando a gente vai na pinacoteca?", "o tia quando a gente faz isso?". É incrivel, "o tia quando que tem uma festa assim?". Então eu imagino essas crianças saindo né, e ir pra outro local, mesmo se cada um conseguir ir pra um prédio, uma casa individual, as próprias crianças vão sentir falta, que à tarde quando vindo da escola, eu fico ali na portaria eu vejo assim, por exemplo, um, uma pessoa aqui, um pai ou uma mãe, eles vão na escola eles trazem assim, umas cinco crianças né, do andar, eles trazem do andar. Ou então, de manhã leva e as próprias crianças já estão acostumadas a isso, ir junto pra escola vim junto, ir pra Pinacoteca... [...] Então isso eu sei que é todo mundo que vai sentir falta de disso, de viver na comunidade. (Jomarina Pires da Fonseca, coordenadora do MSTC, entrevista realizada pela autora em 2009)

Podemos observar com esse relato como o espaço do centro possibilitou uma outra opção de lazer/culturais para levar crianças ou mesmo para os outros moradores poderem usufruir. É importante ressaltar a ausência desse tipo de equipamento público nas periferias, espaços importantes tanto para a formação cultural como para o usufruto de diversão/lazer. Um relato comum das moradoras é a dificuldade de espaços para levar as crianças na periferia, fato este diferente nas áreas centrais, onde se encontram muitas opções.

\section{Luta pelo direito à cidade e segregação socioespacial generificada}

Quando se fala em direito à cidade, é preciso dizer que a sua potência enquanto conceito para a luta coletiva urbana vem se expandindo para muito além da forma como foi pensado quando foi criado, em 1968, pelo filósofo francês Henri Lefebvre. Esse autor parte da segregação socioeconômica para explicar as diferenças de acesso aos direitos dentro da cidade. Segundo ele, 0 morador pobre periférico, não apenas enfrenta longas horas de transporte público ao sair para trabalhar e voltar para casa, como é propositalmente alienado dos espaços urbanos de centralidade. 0 direito à cidade surgiria, portanto, como contrário à alienação provocada pela urbanização segregadora. Ademais, a ideia por trás do termo "direito à cidade" coloca em destaque não apenas quem sofre pela forma segregadora das nossas cidades, mas também o direito a fazer parte das decisões sobre como acontece a urbanização. Isto é, o direito à cidade realizar-se-ia por meio do controle direto das pessoas sobre a forma de habitar a cidade. Nesse caso, a classe trabalhadora seria o "componente-chave" no processo de transformação do espaço urbano, pois, segundo Lefebvre, ela é a única capaz de pôr fim à segregação urbana das nossas cidades, que é dirigida especialmente contra ela. Isto é, estamos nos referindo a um conceito entre a tensão das decisões do planejamento urbano oficial e as reivindicações pelo direito de existir na cidade e usufruir dela de forma igualitária (Lefebvre, 1991; Helene, 2019). 
Nesse sentido, os movimentos de moradia deram um passo fundamental quando passaram a reivindicar programas habitacionais nas áreas centrais das cidades, ocupando os prédios vazios. A luta por moradia expandiu-se para a luta pela reforma urbana e pelo direito à cidade, levantando a necessidade de viver em locais dotados de infraestrutura, equipamentos sociais e empregos. Enquanto muitos movimentos por moradia atuam ocupando glebas vazias nas margens urbanas, afirmando que a ocupação organizada pode reivindicar a correta distribuição de infraestrutura urbana, os movimentos das regiões centrais disputam uma área consolidada, com grande potencial de lucros para a especulação imobiliária e de grande poder simbólico. Essas ocupações também se destacam por trabalhar em uma incongruência do urbanismo, pois apoderam-se de construções abandonadas e subutilizadas, localizadas em áreas extremamente privilegiadas se comparadas às periferias urbanas. Nesse caso, explicitam os problemas de atuação do capitalismo, ressaltando, ao mesmo tempo, o desperdício de infraestrutura e a precarização da vida das classes pobres (Helene, 2009), sobretudo da vida das mulheres. As conquistas em relação à mobilidade e ao acesso à cidade infraestruturada são as mais evidentes. É comum o relato de como os moradores gastavam de três a quatro horas para chegar de seu local de moradia na periferia aos locais de trabalho no centro, e como agora fazem "tudo a pé" ou de bicicleta:

Eu cheguei aqui eu me lembro [...] comecei a trabalhar no shopping Ibirapuera, depois saí, trabalhei no grupo Pão de Açúcar, daí construí família e depois ficou difícil eu trabalhar em firma que tinha horário para sair, horário para entrar, aí eu comecei a sair e comecei a trabalhar em casa de família né, porque antigamente não existia creche nas periferias, como hoje mesmo é muito complicado você encontrar uma creche na periferia. Aí quando surgiu a oportunidade de vim morar aqui, aqui no centro, nossa eu achei incrível né, vir morar aqui no centro, e aqui no centro é tudo mais fácil né, até o emprego, escola, médico, tudo aqui é fácil aqui no centro. Por exemplo, a maior parte das pessoas que mora aqui, no prédio, eles trabalham na economia informal. Por exemplo, eles saem de manhã, vão aventurar na [rua] 25 [de março], na [rua] José Paulino, ali no viaduto Santa Ifigênia... mesmo correndo do rapa, da GCM [Guarda Civil Municipal], da polícia militar, mas eles tão aventurando. Agora você morando lá na periferia, não tem como você pegar uma sacola, vir aqui pra cá pro centro, porque aí você vai depender de uma condução, vai depender do almoço né, pois quem mora aqui no prédio, vai trabalhar na [rua] 25 [de março] e vem almoçar aqui. Então tudo que consegue, qualquer dinheirinho dá para sobreviver. Toda a minha família que mora aqui, eles trabalham aqui no entorno né. $E$ quando depende da condução eles vão de bicicleta. Então é muito prático mesmo, é muito bom morar aqui no centro por causa dessas facilidades que tem. (Jomarina Pires da Fonseca, coordenadora do MSTC, entrevista realizada pela autora em 2009)

Ademais, nesse relato, observam-se as dificuldades de inserção no mercado quando se é mulher e mãe ("daí construí família e depois ficou difícil eu trabalhar em firma") e pior ainda quando as condições urbanas no entorno e a habitação são precárias (" antigamente não 
existia creche nas periferias, como hoje mesmo é muito complicado você encontrar uma creche na periferia"). E como morar em uma área multifuncional e não apenas residencial e destinada às atividades reprodutivas pode trazer uma outra maneira de ela, como mulher, apropriar-se da cidade.

Por meio dos relatos apresentados e da observação do cotidiano dessas ocupações, percebe-se como a qualidade de vida das mulheres mudou substancialmente ao não estarem mais isoladas nas tarefas domésticas nos subúrbios e na periferia. Isso envolve, sobretudo, as facilidades de manutenção das atividades reprodutivas por meio da proximidade de serviços públicos e dos postos de trabalho, em face do que descrevemos antes sobre a constituição das cidades: ter a oportunidade de morar no centro da cidade, onde foram privilegiadas as infraestruturas e a instalação de equipamentos urbanos, ao contrário do que é realizado pelo poder público nas periferias. As conquistas vão da reestruturação das hierarquias de poder dentro do espaço privado e da segurança contra a violência doméstica à reapropriação do espaço público/político e à conquista de um espaço urbano mais adequado às tarefas de reprodução da vida cotidiana.

Podemos dizer que as mulheres participantes desses movimentos sociais engendram uma luta por direito à cidade contra uma segregação socioespacial generificada. Disputam, não apenas o direito viver em espaços apropriados para as tarefas relacionadas à reprodução da vida, mas também lutam pelo valor de uso da moradia e dos espaços relacionados a ela. As mulheres, nesse sentido, ao lutar pelo direito de usufruir de condições inerentes à vida desvelam dimensões fundamentais da luta pelo direito à cidade. As histórias de vida na luta por moradia dessas mulheres explicitam que as diferenças de gênero se articulam de forma indissociável às outras formas de opressão capitalista que estruturam as desigualdades urbanas, engendrando uma luta por direito à cidade marcada por segregações de classe, raça e gênero.

\section{[I] https://orcid.org/0000-0002-8455-4814}

Universidade do Grande Rio, Faculdade de Arquitetura e Urbanismo, Laboratório de Moradia e Terra Urbana da Baixada Fluminense. Duque de Caxias, RJ/Brasil.

crocomila@gmail.com 


\section{Notas}

(1) Este artigo é fruto da minha participação de mais de 15 anos junto a diferentes movimentos de moradia em São Paulo, Campinas e Rio de Janeiro. As informações aqui descritas são resultado de uma metodologia de observação participante e pesquisa-ação. Ainda durante a minha graduação, em 2004, fiz parte da formação do Grupo Risco, um coletivo de arquitetos e urbanistas que acompanhava movimentos de luta pela Reforma Urbana da região de São Paulo e Campinas. Começamos atuando em parceria com a Frente de Luta por Moradia (FLM), que congrega diversos movimentos sociais atuantes no centro da cidade de São Paulo. A partir daí passamos a acompanhar e participar de ações de ocupação de prédios abandonados, manifestações e despejos, dando apoio de maneira a produzir conteúdos (textos e audiovisuais) que pautassem a questão dos problemas da moradia, dos vazios abandonados no centro da cidade e da reforma urbana. Em função dessas ações, o grupo foi contatado também por outros movimentos sociais, como o Movimento dos Trabalhadores Rurais Sem Terra (MST) e o Movimento dos Trabalhadores Sem Teto (MTST). Foi esse trabalho, na prática, que me deu subsídios tanto para realização da minha monografia de graduação, quanto da minha dissertação de mestrado (Helene, 2009). Destaco, ainda, minha atuação na Universidade do Grande Rio (Unigranrio), desde 2014, nas disciplinas de Planejamento Urbano e Regional, Teoria da Habitação e Projeto de Habitação Social. Também sou fundadora e coordenadora, nessa universidade, do Laboratório de Moradia e Terra Urbana da Baixada Fluminense (LabMoTe), no qual realizamos projetos de extensão com o Movimento Nacional de Luta Por Moradia (MNLM) em Duque de Caxias. A parte teórica e conceitual feminista foi aprofundada nos meus pós-doutorados na UQAM (Canadá) em 2016/2017 e no Ippur/UFRJ em 2017/2018. Neste último, desenvolvi e lecionei duas disciplinas com o objetivo de debater as relações entre gênero e território. Agradeço aos meus alunos e às mulheres dos movimentos de moradia pela fundamentação deste artigo. Um ensaio deste trabalho foi apresentado no colóquio Perspectives féministes sur le logement des femmes. Autonomie et émancipation: les femmes dans les mobilisations pour le droit au logement (Helene e Lazarini, 2018) e no V Encontro da Associação Nacional de Pesquisa e Pós-Graduação em Arquitetura e Urbanismo (Helene, 2018).

(2) A princípio, a ideia era criar uma casa de acolhimento para mulheres em situação de violência, mas, com o tempo, a ocupação estruturou-se como um espaço de convivência e referência para as mulheres do MTST. No local, acontecem atividades em três eixos: saúde, geração de renda e formação política e cultural das mulheres. Em abril de 2018, foi realizado um chá de bebê coletivo com 84 gestantes integrantes do movimento na ocupação. Informações adquiridas em palestra dada por Claudia Garcez no seminário "Cidade, Gênero e Interseccionalidade". Disponível em: http://www.labcidade.fau.usp.br/pela-cidade-especial-cidade-genero-e-interseccionalidade-11claudia-garcez/. Acesso em: 17 jun 2019.

(3) Foi, nesse momento, que foi forjada uma ideia de sexualidade que visava ao estabelecimento da família nuclear e do matrimônio como espaços sagrados para a reprodução e a manutenção do capitalismo: "A caça às bruxas foi o primeiro passo de um longo caminho à transformação da atividade sexual feminina em um trabalho a serviço dos homens e da procriação. Nesse processo, foi fundamental a proibição, por serem antissociais e demoníacas, de todas as formas não produtivas, não procriativas da sexualidade feminina. [...] Os julgamentos por bruxaria fornecem uma lista informativa das formas de sexualidade que estavam proibidas, uma vez que eram 'não produtivas': a homossexualidade, o sexo entre jovens e velhos, o sexo entre pessoas de classes diferentes, o coito anal, o coito por trás (acreditava-se que levava a relações estéreis), a nudez e as danças. Também estava proscrita a sexualidade pública e coletiva que prevaleceu durante a Idade Média" (Federici, 2017, pp. 346, 350 e 351). 
(4) Essa máscara de punição foi levada às colônias de forma a punir pessoas escravizadas de forma semelhante.

(5) Consideramos aqui atividades produtivas aquelas relacionadas à produção de mercadorias, bens e serviços; normalmente envolve remuneração sob a forma de salários e são geralmente realizadas por homens. As atividades ditas reprodutivas são aquelas corriqueiramente não vistas como trabalho, sendo não remuneradas ou mal pagas. São as tarefas realizadas por pessoas de uma unidade de convivência para o cuidado de si, para os membros da sua família ou para de uma outra família; ligadas à reprodução da vida, alimentação/nutrição, cuidado, provisão de habitação, limpeza e cuidados; e majoritariamente realizadas por mulheres e, no caso do Brasil, por mulheres negras.

(6) Existem peculiaridades para cada faixa de idade que reiteram essa ideia de dominação na estruturação do poder dentro da unidade familiar: $82 \%$ das agressões a crianças do sexo feminino ( 0 a 11 anos de idade) partiram dos pais - principalmente da mãe, que concentra $42,4 \%$ das agressões. Para as adolescentes de 12 a 17 anos de idade, as agressões dividem-se entre os pais $(26,5 \%)$ e os parceiros ou ex-parceiros $(23,2 \%)$. Para as jovens e as adultas de 18 a 59 anos de idade, o agressor principal é o parceiro ou ex-parceiro, concentrando a metade dos casos. O número mais alarmante para entender essa estrutura de poder dentro da família e sua relação com o gênero é o caso das idosas (acima de 60 anos), nesse caso, o principal agressor são seus próprios filhos (34,9\%). Dados do "Mapa da Violência 2015: Homicídio de mulheres no Brasil" (Waiselfisz, 2015, p. 48).

(7) Trecho originalmente publicado pela autora no blog FeminisUrbana: "Jane Jacobs: uma mãe urbanista". Disponível em: https://feminismurbana.wordpress.com/2018/05/13/jane-jacobsuma-mae-urbanista/. Acesso em: 6 ago 2018.

(8) Zona de sacrifício é um termo surgido no Estados Unidos, cunhado por movimentos sociais afetados por problemáticas ambientais. Nomeia territórios nos quais se sobrepõem diversas iniciativas poluidoras perigosas à saúde e ao meio ambiente, responsáveis por uma série de danos socioambientais. Em geral, nas cidades, as zonas de sacrifício ocupam áreas de habitação de populações de baixa renda, com baixo valor imobiliário e pouca qualidade de equipamentos e infraestrutura urbana. A nomeação dessas zonas auxilia no processo de compreensão de que, dependendo do espaço urbano em que se habita, sofre-se diferentemente as injustiças ambientais inerentes aos processos produtivos capitalistas. Isto é, no capitalismo, assim como se produz de forma diferente e se consome de forma desigual, acontece uma distribuição desigual dos riscos e impactos socioambientais.

(9) Dados do IBGE de 2015 apontam que as mulheres na cidade morrem em número maior que os homens de doenças respiratórias (relacionadas à poluição atmosférica); de neoplasmas (tumores), doenças endócrinas, nutricionais e metabólicas (relacionadas à toxicidade industrial); e de doenças do trato geniturinário (totalizando 40,99\% dos óbitos femininos e 31,02\% dos óbitos masculinos). No caso das crianças, dos 100 municípios mais populosos do País, Duque de Caxias é o município com a maior proporção de crianças entre as pessoas internadas por diarreia, com 77,1\%; e internação média de 58,6 pessoas por 100 mil hab (Kronemberger, 2013, p. 7). 
(10) Seria interessante a realização de pesquisa quantitativa sobre essas informações dentro das ocupações. No entanto, é preciso ressaltar que a presença feminina é tão superior nos movimentos de moradia que é facilmente percebida por contraste visual. Como já explicitado em outro trabalho, pode-se dizer que quase $80 \%$ dos participantes são mulheres (Helene e Lazarini, 2018). Claudia Garcez, coordenadora estadual do MTST, afirma que 60\% dos cargos de coordenação do MTST são compostos por mulheres (Disponível em: http://www.labcidade. fau.usp.br/pela-cidade-especial-cidade-genero-e-interseccionalidade-11-claudia-garcez/.Acesso em: 17 jun 2019).

(11) Martinelli (2018).

(12) Transcrição de entrevista do filme "LEVA", Dir: Juliana Vicente e Luiza Marques, 55'00", HD, Canal Futura, 2011. Disponível em: https://youtu.be/xn2um8xhc4o. Acesso em: 17 jun 2019.

(13) A exemplo de caso, segundo o Censo Comunitário Rural de 2000 (Confederação Nacional Agrária realizada em Brasília), 89\% dos proprietários de terra são homens.

(14) Um grande impedimento para as mulheres não romperem ou denunciarem um agressor é o fato de terem filhos - o que ocorreu em 78,72\% dos atendimentos do Ligue 180 (dados de 2016).

(15) A entrevista foi parte do trabalho final de graduação de Maria Pia Fahham (Fahham, 2017).

(16) Transcrição de entrevista do filme "LEVA", Dir: Juliana Vicente e Luiza Marques, 55'00", HD, Canal Futura, 2011. Disponível em: https://youtu.be/xn2um8xhc4o. Acesso em: 17 jun 2019.

(17) Transcrição de entrevista realizada no filme “LEVA", Dir: Juliana Vicente e Luiza Marques, 55’00", HD, Canal Futura, 2011.

\section{Referências}

AGREST, D. (2006). “À margem da arquitetura: corpo, lógica e sexo”. In: NESBITT, K. (org.). Uma nova agenda para a arquitetura. Antologia teórica (1965-1995). São Paulo, Cosac Naify.

ALFONSIN, B. de M. (2006). “Cidade para todos/cidade para todas - vendo a cidade através do olhar das mulheres". In: FERNANDES, E. e ALFONSIN, B. (coords.) Direito urbanístico-estudos brasileiros e internacionais. Belo Horizonte, Del Rey.

ALVES, A. E. S. (2013). Divisão sexual do trabalho: a separação da produção do espaço reprodutivo da família. Trab. Educ. Saúde [on-line], v. 11, n. 2, pp. 271-289.

ANDRADE, L. (2013). Reverso de um espetáculo urbano: desafios e perspectivas para uma arquitetura habitacional popular. Rio de Janeiro, Casa 8.

ARANTES, P. F. (2002). Arquitetura nova: Sérgio Ferro, Flávio Império e Rodrigo Lefèbvre - de Artigas aos mutirões. São Paulo, Editora 34.

FAHHAM, M. P. (2017). O mutirão de autogestão pela perspectiva da mulher. Trabalho Final de Graduação apresentado à Escola da Cidade/SP. São Paulo. 
FAUSTINO, C. e FURTADO, F. (2013). Indústria do petróleo e conflitos ambientais na Baía de Guanabara: o caso do Comperj. Relatório da Missão de Investigação e Incidência Plataforma Dhesca-Relatoria do Direito Humano ao Meio Ambiente. Rio de Janeiro.

FEDERICI, S. (2017). Calibã e a bruxa: mulheres, corpo e acumulação primitiva. São Paulo, Elefante.

GOHN, M. da G. (1991). Movimentos Sociais e luta pela moradia. São Paulo, Loyola.

GONZAGA, T. de O. (2011). A cidade e a Arquitetura também mulher: planejamento urbano, projetos arquitetônicos e gênero. São Paulo, Annablume.

HELENE, D. (2009). A guerra dos lugares na ocupações de edifícios abandonados do centro São Paulo. Dissertação de Mestrado. São Paulo, Universidade Estadual de São Paulo.

(2018). Mulheres e direito à cidade a partir da luta dos movimentos de moradia. In: V ENANPARQ. Salvador, FAUFBA.

(2019). Editorial. Revista Coletiva - Dossiê Direito à Cidade. Fundação Joaquim Nabuco, v. 24, p. 1.

HELENE, D. e LAZARINI, K. (2018). “Autonomie et émancipation: les femmes dans les mobilisations pour le droit au logement" In: COLLOQUE PERSPECTIVES FÉMINISTES SUR LE LOGEMENT DES FEMMES. Anais... UQAM, Montreal.

HIRATA, H. (2014). Gênero, classe e raça Interseccionalidade e consubstancialidade das relações sociais. Tempo soc. [online], v. 26, n. 1, pp. 61-73.

IGNÁCIO, J. (2018). Luta: substantivo feminino: Um olhar de gênero às ocupações urbanas e direito à moradia. Trabalho de Conclusão de Curso. Rio de Janeiro, Universidade do Grande Rio.

ITIKAWA, L. (2015). Mulheres na periferia do urbanismo - Informalidade subordinada, autonomia desarticulada e resistência em Mumbai, São Paulo e Durban. Buenos Aires, Clacso, Ideas, Codesria.

JACOBS, J. (2000). Morte e vida de grandes cidades. São Paulo, Zahar.

KERGOAT, D. (2003). “Divisão sexual do trabalho e relações sociais de sexo”. In: EMílıO, M. et al. (orgs.). Trabalho e cidadania ativa para as mulheres: desafios para as políticas públicas. São Paulo, Coordenadoria Especial da Mulher, pp. 55-63.

KRONEMBERGER, D. (2013). Análise dos impactos na saúde e no Sistema Único de Saúde decorrentes de agravos relacionados a um esgotamento sanitário inadequado dos 100 maiores municípios brasileiros no período 2008-2011. Relatório Final. Oscip Instituto Trata Brasil.

LATENDRESSE, A. (2005). La ville: un espace investi par les femmes et le groupes de femmes?. . In: 4 CONGRÈS INTERNATIONAL DES RECHERCHES FÉEMINISTES DANS LA FRANCOPHONIE PLURIELLE. Atas... Ottwa, Les éditions du remeu-ménage.

LAZARINI, K. (2014). Luta por moradia e autogestão em Buenos Aires: da crise à construção popular do hábitat. Dissertação de Mestrado. São Paulo, Universidade de São Paulo.

LEFEBVRE, H. (1991). O direito à cidade. São Paulo, Morais.

MARTINELLI, F. (2018). "Primeira-dama pé no barro". Natalia Szermeta é a companheira de Boulos na liderança do MTST e coordena 55 mil famílias em 13 estados. Universa UOL, 11 de maio Disponível em: https://universa.uol.com.br/especiais/natalia-szermeta\#primeira-dama-pe-nobarro?cmpid=copiaecola. Acesso em: 17 jun 2019.

OKIN, S. M. (2008). Gênero, o público e o privado. Estudos Feministas. Florianópolis, v. 16, n. 2. 
PEREIRA, T. (2013). Sustentabilidade e justiça ambiental na Baixada Fluminense: identificando problemas ambientais a partir das demandas ao Ministério Público. Cadernos Metrópole. São Paulo, v. 15, n. 29, pp. 339-358.

PERROT, M. (1988). Os excluídos da História: operários, mulheres e prisioneiros. Rio de Janeiro, Paz e Terra.

PINHEIRO, L.; FONTOURA, N. e PEDROSA, C. (2012). "Situação das trabalhadoras domésticas no país". In: CASTRO, J. A. de e ARAÚJO, H. E. (orgs.). Situação social brasileira. Brasília, Ipea, cap. 6, pp. 93-124.

PISCITELLI, A. (2002). Re-criando a (categoria) mulher. Textos didáticos, v. 48, pp. 7-42.

PRONI, M. W. e GOMES, D. C. (2015). Precariedade ocupacional: uma questão de gênero e raça. Estud. av. [online], v. 29, n. 85, pp. 137-151.

RAUL, J. (2015). Mulheres negras, movimentos sociais e direito à cidade: uma perspectiva para as políticas públicas. e-metropolis: Revista eletrônica de Estudos Urbanos e Regionais, v. 1, pp. 46-53.

ROLNIK, R.; REIS, J.; SANTOS, M. P. e IACOVINI, R. F. G. (2011). Como fazer valer o direito das mulheres à moradia? Relatoria Especial da ONU para o Direito à Moradia Adequada.

SAFFIOTTI, E. (1979). A mulher na sociedade de classes: mito e realidade. Petrópolis, Vozes.

SANTORO, P. F. (2008). Gênero e planejamento territorial: uma aproximação. In: XVI ENCONTRO NACIONAL DE ESTUDOS POPULACIONAIS. Anais... Caxambu-MG, Abep.

SCOTT, J. (1988). Gênero: uma categoria útil de análise histórica. Educação e Realidade, v. 16, n. 2, pp. 5-22.

SILVA, J. M. (2003). Um ensaio sobre a potencialidade do uso do conceito de gênero na análise geográfica. Revista de História Regional. Ponta Grossa, v. 8, n. 1, pp. 31-45.

TAVARES, R. B. (2015). Indiferença à diferença: espaços urbanos de resistência na perspectiva das desigualdades de gênero. Tese de Doutorado. Rio de Janeiro, Universidade Federal do Rio de Janeiro.

WAISELFISZ, J. J. (2015). Mapa da Violência 2015: homicídio de mulheres no Brasil. Brasília, Secretaria Especial de Políticas para as Mulheres - Ministério das Mulheres, da Igualdade Racial e dos Direitos Humanos.

Texto recebido em 18/mar/2019

Texto aprovado em 2/jun/2019 